\title{
Multiple mechanisms for recency with vowels and consonants
}

\author{
MARCO W. BATTACCHI \\ University of Bologna, Bologna, Italy \\ GIOVANNA M. PELAMATTI \\ University of Padua, Padua, Italy \\ and \\ CARLO UMILTÀ \\ University of Parma, Parma, Italy
}

\begin{abstract}
Three experiments were conducted to test the hypothesis that the difference in recency effect between vowel-contrasting and stop-contrasting lists of syllables in immediate ordered recall can be explained by item discriminability and regular short-term memory mechanisms, without any recourse to echoic memory or precategorical acoustic storage (PAS). In Experiment 1, the shortterm memory mechanisms were manipulated by reducing amount of output interference and length of retention interval. The partial-report technique was used. The most important finding was the usual final-position recency effect (difference in recall between the fifth and sixth serial positions) for the vowel lists but not for the stop lists, regardless of the type of report. Thus the PAS theory could not be rejected. In Experiments 2 and 3, the last item was differentiated from the other items of the list, either by lengthening the interstimulus interval between the last and the next-to-last (Experiment 2) or by increasing the intensity of the last item (Experiment 3). In both cases, an increase of the final-position recency effect was found even for stop lists. Since a drop in recall errors was also obtained for the fourth item when its intensity was increased (von Restorff effect), this final-position recency effect for stop lists is likely to be due to item discriminability, and not to echoic memory for the last item. Item discriminability appeared to be the critical factor.
\end{abstract}

The present study dealt with the recency effect in ordered recall of auditorily presented lists of consonantvowel syllables that differ only in either their stop consonant or their vowel. The recency effect is defined here as the improved performance on the last serial position of a memorized list compared with the next-to-last position. A widely accepted interpretation of the recency effect is based on the theory of echoic memory or precategorical acoustic storage (Crowder \& Morton, 1969). According to this interpretation, the last item heard has an extraordinary representation in echoic memory, because it is the only item that does not suffer from interference or masking by any subsequent input (Crowder, 1978). This extraordinary representation can be read out, while still lingering in echoic memory, to supplement the regular short-term memory for those final items.

There is abundant evidence that a reliable recency effect is obtained for lists of consonant-vowel syllables that differ in their vowels, but not for those that differ in their stop consonants (Crowder, 1971, 1973). One explanation of why a recency effect occurs only for vowel-contrasting

Address correspondence to Marco W. Battacchi, Department of Psychology, Viale Berti Pichat 5, I-40127 Bologna, Italy. lists is that read-out from echoic memory is not possible when stops are the distinctive phonemes, because the representation of stops in echoic memory is subject to an extremely rapid loss of information (Crowder, 1973, 1986; Pisoni, 1973). Another explanation is based on the low discriminability of stop consonants; if the representation of stops in echoic memory is highly confusable, it cannot be of any help in recall even when available (see Crowder's [1981, 1983] revised model of precategorical acoustic storage). In fact, Darwin and Baddeley (1974) found that the absence of a recency effect was not limited to stop lists, but also extended to lists of syllables whose distinctive phonemes were highly confusable synthetic vowels. In contrast, lists of natural syllables that differed in highly dissimilar consonants yielded a clear-cut recency effect (see also Battacchi, Pelamatti, Tessarollo, \& Umiltà, 1978). At any rate, whichever explanation is accepted, the explanations concur in assuming that, in the case of stops, the echoic representation is unable to supplement regular short-term memory.

However, a third explanation, which does not make this assumption, is possible. According to it, item discriminability and regular short-term memory mechanisms are sufficient conditions for explaining the difference in recency between vowel-contrasting and stop-contrasting 
lists, without any recourse to echoic memory (see also Massaro, 1972). The difference in recency effect between stop-contrasting and vowel-contrasting lists would depend on the higher confusability of stops than of vowels. This confusability hypothesis rests on two assumptions: (1) the closer to the terminal position the items are, the more their recall is negatively affected by general factors such as output interference (Posner, 1964), and (2) the more confusable the items are, the less they can resist this negative influence. The latter effect may not be successfully counteracted by factors that are known to facilitate recall of the last item, such as temporal distinctiveness (Glenberg \& Swanson, 1986).

To collect evidence for the confusability explanation, we conducted three experiments. In Experiment 1, we reduced the amount of output interference and the length of the retention interval. In Experiments 2 and 3, the last item was differentiated from the other items in the list without changing its spectral features. This differentiation was done either by lengthening the interstimulus interval between the last and the next-to-last item or by increasing the intensity of the last item. In Experiment 1, we manipulated factors related to short-term memory mechanisms that are known to decrease the recall probability of the last item. In the other two experiments, we manipulated the informational value or absolute discriminability within the list. In both cases, the confusability theory would predict an increase in the recall probability of the last item, and consequently an increase in the recency effect, even in ordered recall of stop lists.

\section{EXPERIMENT 1}

Output interference, as well as length of retention interval, was reduced in an experiment in which lists of vowel-contrasting and stop-contrasting syllables had to be recalled under instructions of either partial or full report. (Partial report is intended here to mean the postcued recall of only a selected part of the list.) If the difference in recency effect between vowel and stop lists is reduced by partial report, the hypothesis that the recency effect depends on item discriminability and regular short-term memory for the items will be supported. In contrast, if this difference is not affected by partial report, the hypothesis that the recency effect depends on the properties of item representation in echoic memory cannot be rejected. It should be noted that almost all our information about echoic memory comes from immediate ordered recall. Finding new evidence for echoic memory by manipulating the basic immediate-memory paradigm is, therefore, of some value.

Four stimulus conditions were employed in the experiment. They differed in terms of the type of syllables and on whether the informative part of the syllables preceded or followed the redundant part. In other words, we had vowel-contrasting lists of vowel-consonant (VC) syllables and stop-contrasting lists of CV syllables, in which the information about the distinctive phoneme was car- ried by the initial part of the acoustic segment. Similarly, we had vowel-contrasting lists of CV syllables and stopcontrasting lists of VC syllables, in which information was carried by the final part. Crowder (1973) already found that, with full report, reversing the order of the informative and uninformative parts makes no difference for consonant syllables. However, we decided to test both orders, since Crowder did not use the partial-report procedure.

\section{Method}

Stimuli. The stimuli were synthetic syllables created on an OVE III synthesizer. There were two sets of three stimuli that differed in the consonant sound: /pa, ta, $\mathrm{ka} /$ and /ap, at, ak/. There were also two sets of three stimuli that differed in the vowel sound: /pe, pi, pu/ and /ep, ip, up/. Each syllable was $200 \mathrm{msec}$ in duration. From each of the four sets of syllables, 15 lists of six syllables were constructed. In every list, the syllables were presented twice in quasirandom strings. The lists were recorded on a tape recorder and were presented binaurally to the subjects through headphones.

Procedure. There were eight experimental conditions, four for the full-report paradigm and four for the partial-report paradigm. For each report, the four stimulus conditions were: (1) VC syllables differing in the stop sound, (2) CV syllables differing in the vowel sound, (3) CV syllables differing in the stop sound, and (4) VC syllables differing in the vowel sound.

For every stimulus condition, there were 15 lists of six syllables each. At the beginning of each list, the subjects heard a tone as the warning ready signal followed, after an interval of $1 \mathrm{sec}$, by the first syllable in the list. The other syllables were presented at a rate of one every $1 / 2 \mathrm{sec}$. The interlist interval was $10 \mathrm{sec}$.

In the case of full report, the subjects were instructed to write down on an appropriate sheet of paper the syllables they had heard, immediately after presentation of the last item and by following the order of the sequence. In the case of partial report, every list was followed, after an interval of $1 / 2 \mathrm{sec}$, by a tone of one of three pitches: low (indicating to report the first and second items in the list), middle (third and fourth items), or high (fifth and sixth items). The subjects were instructed to write down the pair of items cued by the tone in the same order as their presentation. Practice trials with different lists (but with the same cue tones) ensured that subjects understood the instructions.

Subjects. Twenty-four students (12 males and 12 females) with no previous experience in speech perception experiments participated. None of them was known to have any hearing disorder.

For each of the four stimulus conditions, 12 of the subjects (6 males and 6 females) participated in full report and 12 in partial report.

\section{Results}

The results are shown in Figure 1. Overall recall performance was worse when the informative part of the syllable followed the uninformative part. In particular, full report was exceedingly difficult when the informative consonant followed the uninformative vowel (/ap, at, ak/). We return to this rather unusual finding below.

The results are presented according to analyses of variance (ANOVAs) for mixed designs, with .05 rejection regions, performed only on Positions 5 and 6 . Separate analyses were performed for Conditions 3 and 4 , in which the informative part of the syllable preceded the uninformative part, and for Conditions 1 and 2, in which the informative part followed the uninformative one. Each ANOVA had three main factors: type of report (partial 


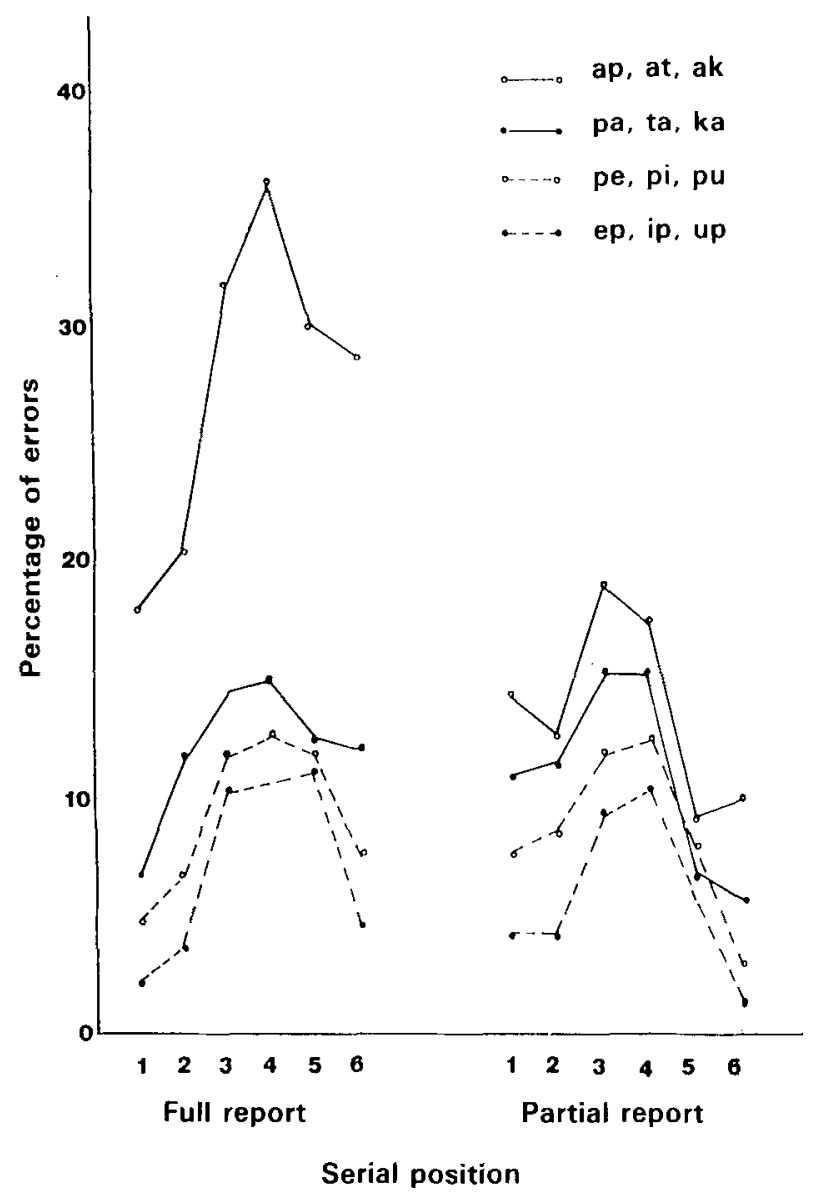

Figure 1. Serial curves for partial and full report.

vs. full) as the between-subject factor, and stimulus condition (stops vs. vowels) and serial position (5th vs. 6th) as within-subject factors. For sake of clarity, percentages of errors are reported, although the analyses were performed on arcsine transformations. Note that the serialposition factor actually measured the recency effect.

With regard to performance on Positions 5 and 6, recall was significantly better for partial than for full report $\left[F(1,22)=14.07, M S_{\mathrm{e}}=628.8\right.$, and $F(1,22)=19.85$, $M S_{\mathrm{e}}=3,745.0$, respectively], for vowel lists than for stop lists $\left[F(1,22)=7.99, M S_{\mathrm{e}}=363.0\right.$, and $F(1,22)=$ $20.39, M S_{\mathrm{e}}=4,040.4$, respectively], and for the last position than for the next-to-last position $[F(1,22)=26.86$, $M S_{\mathrm{e}}=301.4$, and $\left.F(1,22)=5.86, M S_{\mathrm{e}}=155.5\right]$. That turned out to be true, regardless of whether the informative part of the syllable preceded or followed.

However, the final-position recency effect was entirely due to the vowel condition, for which a recency effect was found regardless of the type of report, whereas no recency effect was ever found for stop lists. This difference in recency effect was statistically significant: $F(1,22)$ $=9.46, M S_{\mathrm{e}}=141.4$, and $F(1,22)=7.27, M S_{\mathrm{e}}=$ 154.5 , respectively, for the interaction of stimulus condition with serial position. No other terms were significant.
Thus, partial report did not affect the difference in recency between vowel and stop lists. An interesting collateral finding was that, this result notwithstanding, partial report succeeded in affecting recall performance: a glance at Figure 1 shows dramatic effects of recall mode on performance.

To this point, recency has been defined as the improved performance on the last serial position compared with that on the next-to-last position (final-position recency). However, a second, broader kind of recency may occur, namely the improved recall of the terminal part of a list compared with that of the central part. Since in the partialreport condition of the present experiment only one pair of items had to be recalled for each trial, this second kind of recency can be operationally defined as the improved performance on the last two positions compared with that on the two middle positions. As is shown in Figure 2, where the whole range of serial positions are considered, with the recall errors for each pair pooled, partial report markedly changed the shape of the recall curves for both vowel and stop lists. It also succeeded in introducing a reliable recency effect for stop lists.

When the informative part of the syllables preceded the uninformative part, namely the sets / pa, ta, $\mathrm{ka} / \mathrm{and} / \mathrm{ep}$, ip, up/, partial report resulted in a decrease in recall errors on the final two positions for both vowel and stop lists. The error rate dropped from $12.76 \%$ with full report to $6.83 \%$ with partial report for the stop list, and from $8.05 \%$ to $3.75 \%$ for the vowel lists. As a consequence, partial report resulted in an overall increase in the differ-

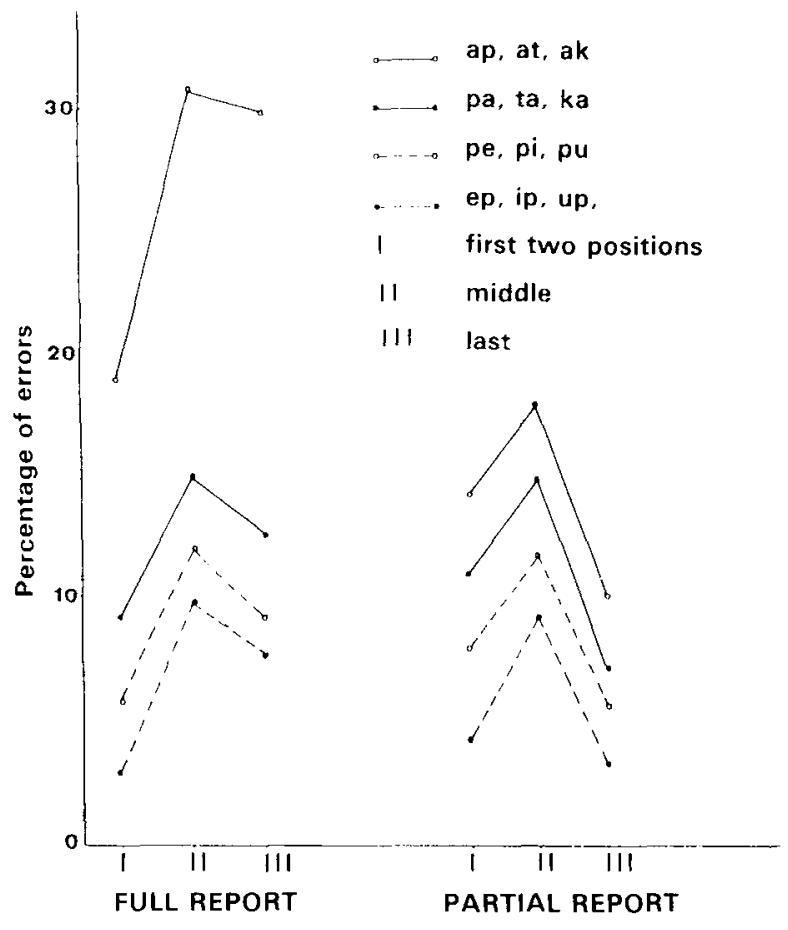

Figure 2. Serial curves for partial and full report (serial positions grouped by twos). 
ence between the middle two and the last two positions; that is, the partial report procedure increased this type of recency effect for both vowels and stops. The changes brought about by type of report were significant [interaction of type of report with serial position, $F(2,44)=$ $\left.12.37, M S_{\mathrm{e}}=155.7\right]$ and independent of stimulus condition [interaction of type of report with stimulus condition, $F(1,22)<1]$.

Nearly the same pattern of results was found when the informative part of the syllables followed the uninformative part (sets /ap, at, ak/ and /pe, pi, pu/). Partial report brought about a significant decrease in recall errors on the last two positions, but this decrease was remarkably high for the VC stop lists. Actually, the error rate on the last two positions dropped from $30.82 \%$ to $9.99 \%$ for the stop lists, and from $9.53 \%$ to $5.35 \%$ for the vowel lists. As a consequence, not only the interaction of type of report with serial position was significant $[F(2,44)=$ $\left.8.27, M S_{\mathrm{e}}=393.2\right]$, but also the interaction of type of report with stimulus condition $\left[F(1,22)=9.27, M S_{\mathrm{e}}=\right.$ 1,397.5]. Apparently, the interaction was significant due to the unusual overall difficulty of the stop lists when the informative part of the syllables followed the uninformative part (see Figures 1 and 2).

This unexpected finding deserves a closer examination. A tentative explanation may be that the VC syllables/ap, at, ak/-sounded, due to unreleased voiceless stops in their terminal position, very unfamiliar to Italian ears, and were for this reason highly confusable. Some support for this hypothesis was obtained from an experiment in which 8 American students in Padua and 15 Italian students were required to fully recall both the $\mathrm{CV}$ and $\mathrm{VC}$ lists. An ANOVA showed a significant difference between American and Italian subjects in recall of $\mathrm{CV}$ and VC syllables, with the nationality $\times$ type of syllable interaction being significant $\left[F(1,21)=7.25, M S_{\mathrm{e}}=250.1\right]$. The error rate of American subjects with CV lists (35\%) and VC lists (39\%) did not differ from that of Italian subjects with the CV lists (34\%), whereas the Italian subjects' error rate on VC lists was much higher (58\%). Apparently the difficulty on VC lists was limited to Italian subjects.

\section{Discussion}

The hypothesis that the difference in final-position recency effect between vowel and stop lists depends on a different representation for vowels and stops in echoic memory cannot be rejected on the basis of our findings. Of course, the more general hypothesis that the finalposition recency effect depends on an auditory sensory storage also is compatible with the present results.

Perhaps our test was not as good as it could have been. After all, only a few factors affecting overall recall were manipulated by comparing partial and full report, and perhaps they were not manipulated effectively enough. However, partial report was effective on the recency part of the list also for stops, provided that the recency effect is defined as the difference in recall between the central and the terminal parts of the lists.
A related criticism would be that our partial-report condition required recall of two items. It follows that only the next-to-last item, in the final pair, was completely free from output interference, and therefore its recall was facilitated relative to that of the last item. However, the absence of any recency effect for stop lists cannot be explained in this way, because the drop in errors with partial report was larger for the fifth position than for the final position only in the unusually difficult condition of stop syllables in VC order.

Another criticism that could be raised is that our partialreport condition induced a 2-2-2 grouping of the items, whereas a 3-3 grouping is more likely or at least possible in the full-report condition; if there tended to be primacy and recency effects within groups (Ryan, 1969a, 1969b), a 2-2-2 grouping would favor all the items, whereas a 3-3 grouping would favor only Items $1,3,4$, and 6 (thus enhancing the recency effect). As a consequence, compared with the supposed 3-3 grouping of full report, the 2-2-2 grouping of partial report would favor Items 2 and 5, thus reducing the recency effect. However, this criticism can easily be ruled out if we consider that, whatever factor was actually manipulated by switching from full to partial report, the type of report appeared to be completely ineffective, as far as final recency is concerned. Only the stimulus condition (vowels vs. stops) was effective.

In fact, the most interesting result of the present experiment was the dissociation between last-position and general recency. The experiment was able to separate two kinds of recency effect by showing that they are sensitive to different factors and hence depend on different memory processes. What happens within the last two serial positions is independent of what happens between the central positions and the terminal ones.

Experiments 2 and 3 addressed the question of what stimulus factors contribute to last-position recency.

\section{EXPERIMENT 2}

In lists of six stop-contrasting syllables, the interstimulus interval (ISI) between the fifth and the sixth items was made twice as long as the ISI between any other pair of items in the list. In this way, the temporal distinctiveness of the last item was increased without changing its stimulus characteristics. Based on the hypothesis that the attentional value, and hence the discriminability within the list, would thus be enhanced, the confusability theory would predict an improvement in the recall probability of the last item. Consequently, a difference in recency effect between the experimental condition of the doubled ISI before the last item and the usual condition of constant ISI throughout the list was expected.

\footnotetext{
Method

Stimuli. The set of stimuli / pa, ta, ka/ from Experiment 1 was used. The ISI was $400 \mathrm{msec}$, except that the ISI between the fifth and sixth items in the experimental condition was $800 \mathrm{msec}$. The number of lists and the way they were constructed were the same as in Experiment 1.
} 
Procedure. There were two stimulus conditions: (1) the ISI between the fifth and sixth items was twice as long as the ISI between any other pair of items (experimental condition), and (2) the ISI remained constant. The procedure was the same as in the full-report condition of Experiment 1.

Subjects. Twenty university students (10 males and 10 females) with no previous experience in speech perception experiments participated. None of them was known to have any hearing disorder. Ten subjects participated in the experimental condition, and 10 in the control condition.

\section{Results}

As shown in Figure 3, lengthening the ISI between the fifth and the sixth positions resulted in a marked improvement in recall performance for the last item. An ANOVA was performed taking into account two main factors: stimulus condition (ISI constant vs. ISI varied) as the between-subject factor, and serial position (the six serial positions) as the within-subject factor. The main effect of stimulus condition was not significant $[F(1,38)=2.1$, $M S_{\mathrm{e}}=882.8$ ], whereas the main effect of serial position and the interaction of stimulus condition with serial position were both significant $\left[F(5,190)=36.84, M S_{\mathrm{e}}=\right.$ $3,290.0$, and $F(5,190)=4.21, M S_{\mathrm{e}}=376.2$, respectively]. The last result was due to the difference between the two stimulus conditions in the recency part of the list, as attested by the fact that the difference between the fifth and the sixth items was significant for the experimental condition $\left[F(1,19)=37.31, M S_{\mathrm{e}}=2,561.6\right]$, but not for the control condition $[F(1,19)<1]$. Lengthening the ISI succeeded in producing a recency effect also in the stopcontrasting list.

\section{Discussion}

Our hypothesis was that lengthening the ISI between the last two serial positions would increase the attentional value of the last item, and thus its discriminability within the list, due to temporal isolation. As predicted, a recency effect was found, even for stop lists. However, before accepting the results as evidence in favor of our hypothesis, we must consider whether this finding can be accounted for within the framework of an echoic-memory hypothesis.

According to Crowder's (1983) explanation of recency and suffix effects in terms of lateral inhibition in echoic memory, recency is produced because the last item (1) has less time to undergo inhibition than the others, and (2) has only one direction from which inhibition comes, unlike all the earlier items. However, it may be contended that

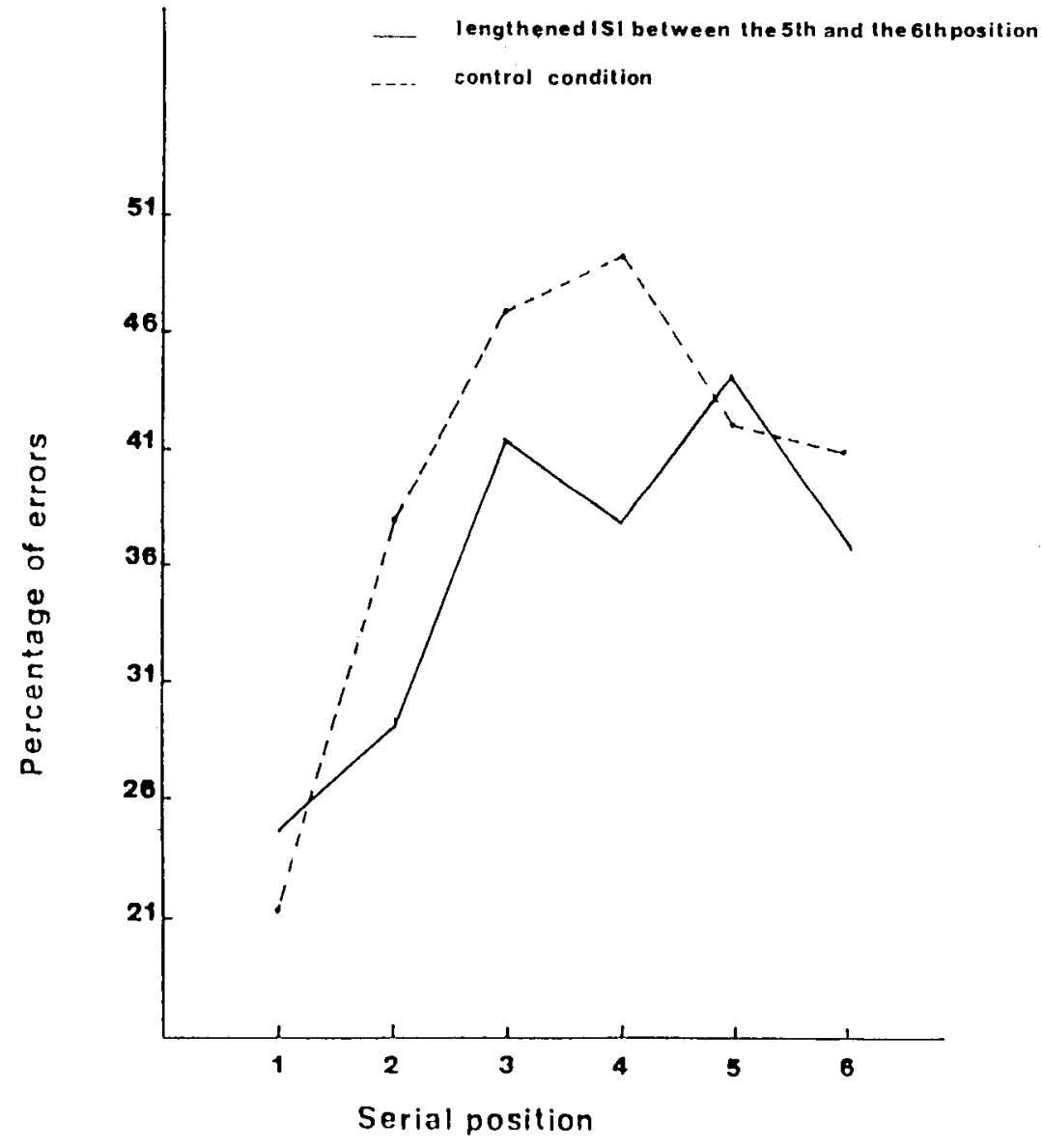

Figure 3. Serial curve for the condition of increased interstimulus interval (ISI) between the fifth and the sixth items, compared with the control condition (stop syllables). 
echoic-memory traces for stops are so similar or so rapidly decaying that they can be of some help in recall only if the last item suffers from no inhibition. It would follow that temporally isolating the last item reduced inhibition in both directions and that, accordingly, the last-item recency was improved. Therefore, it seemed advisable to look for further evidence for choosing between the two alternative explanations.

\section{EXPERIMENT 3}

In lists of six stop-contrasting syllables, the intensity of the last item was increased while the intensity of the other items was held constant. Once again, the attentional value, and consequently the discriminability, of the last item was increased by differentiating it within the list, without changing its distinctive features. In this experiment, one additional condition was included, in which the intensity of the fourth item was increased instead.

\section{Method}

Stimuli. The set /pa, ta, $\mathrm{ka} /$ of the previous experiments was used. The intensity of all the items was $0.4 \mathrm{~V}$, except for the sixth item in one condition and the fourth in the other condition. The intensity of these two items was $1.2 \mathrm{~V}$. The number of lists and the way of constructing them were the same as in the previous experiment. Procedure. There were two experimental conditions: (1) increased intensity of the sixth item, and (2) increased intensity of the fourth item. The procedure was the same as in Experiment 2, which also provided the control condition.

Subjects. Twenty subjects ( 10 males and 10 females) with no previous experience in speech perception experiments took part in the experiment. None of them was known to have any hearing disorder. Ten subjects participated in the first stimulus condition, and 10 in the second.

\section{Results}

Two separate ANOVAs were performed, taking into account two main factors: stimulus condition (intensity constant vs. intensity varied) and serial position (the six serial positions). In one, the control condition taken from

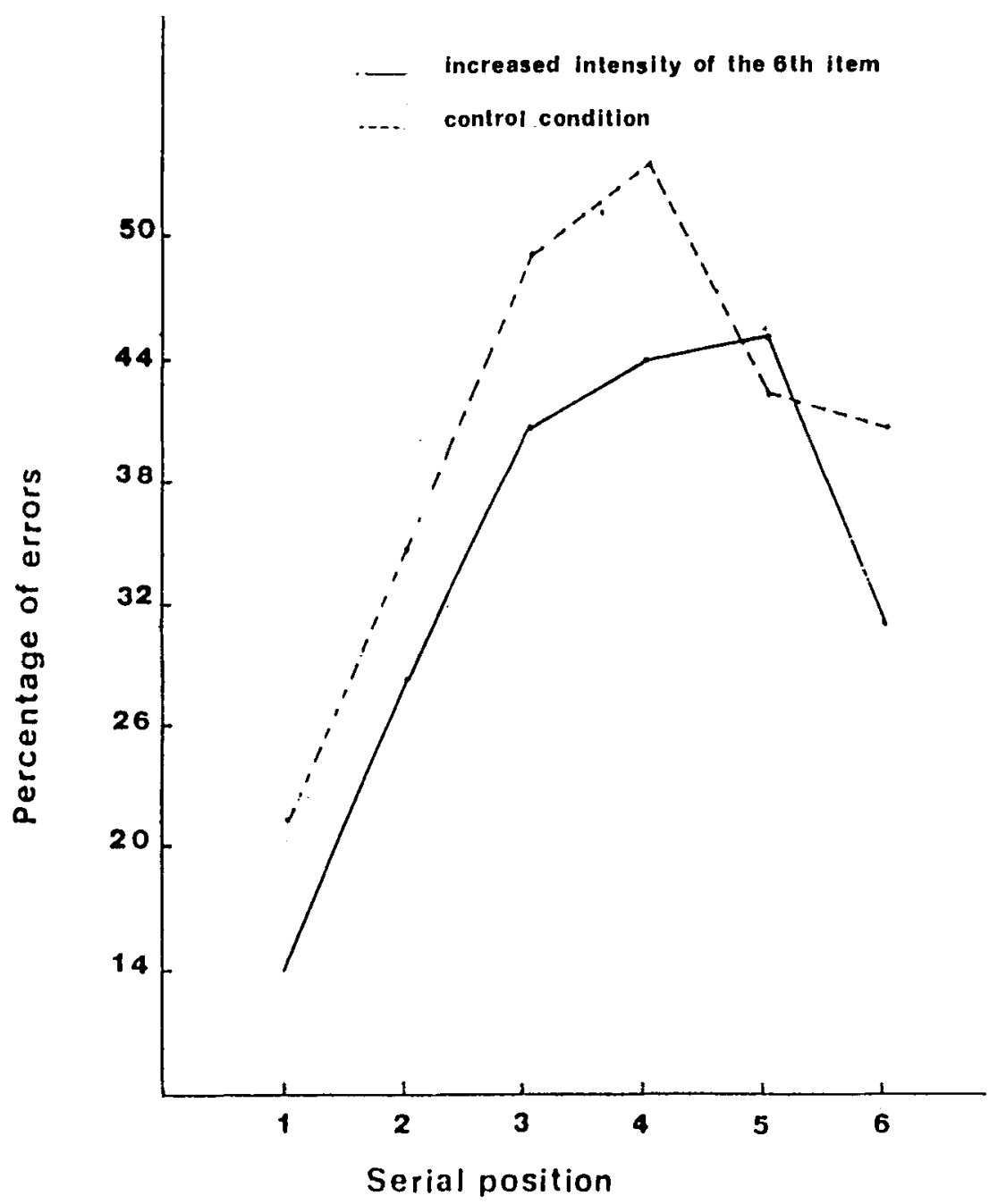

Figure 4. Serial curve for the condition of increased intensity of the last item, compared with the control condition (stop syllables). 
the previous experiment was compared with the first experimental condition, and in the other, the same control condition was compared with the second experimental condition.

As shown in Figure 4, increasing the intensity of the last item produced a significant recency effect also for stop lists. The ANOVA showed that both main effects were significant: stimulus condition $\left[F(1,38)=6.13, M S_{\mathrm{e}}\right.$ $=2,160.0]$ and serial position $\left[F(5,190)=64.83, M S_{\mathrm{e}}\right.$ $=4,750.6]$. Also the interaction of stimulus condition with serial position was significant $\left[F(5,190)=2.96, M S_{\mathrm{e}}\right.$ $=216.6]$. This finding was checked by taking into account only the difference in recall between the fifth and sixth items. The ANOVA showed that the difference was significant $\left[F(1,19)=31.11, M S_{\mathrm{e}}=2,248.5\right]$.

However, increasing the intensity of the fourth item also improved recall performance for that item, in comparison with the control condition (see Figure 5). The ANOVA showed that the main effect of stimulus condition was not significant $\left[F(1,38)=2.68, M S_{\mathrm{e}}=1,000.0\right]$, whereas the main effect of serial position and the interaction of stimulus condition with serial position were sig- nificant $\left[F(1,38)=33.81, M S_{\mathrm{e}}=2,917.5\right.$, and $F(5,190)$ $=5.44, M S_{\mathrm{e}}=469.1$, respectively] .

\section{Discussion}

The improvement of recall performance for the last serial position when the intensity of the last item is increased could be explained in terms of echoic memory only with great difficulty. In fact, Crowder's (1983) model predicts this result only if the last item is made dissimilar from the others in its spectral features, and that was not the case in this experiment. Furthermore, even if one were willing to cling to the echoic-memory hypothesis, for example, by claiming that the greater intensity protects the echoic trace from a too rapid decay or overwrites the inhibiting information coming from the next-to-last item, this explanation could not hold for the improved performance on the fourth serial position. In point of fact, this last effect is but another instance of the well-established von Restorff (1933) effect, which occurs when one of the items in a list is made heterogeneous with regard to the others. It can be accounted for by regular short-term memory processes and item discriminability within the

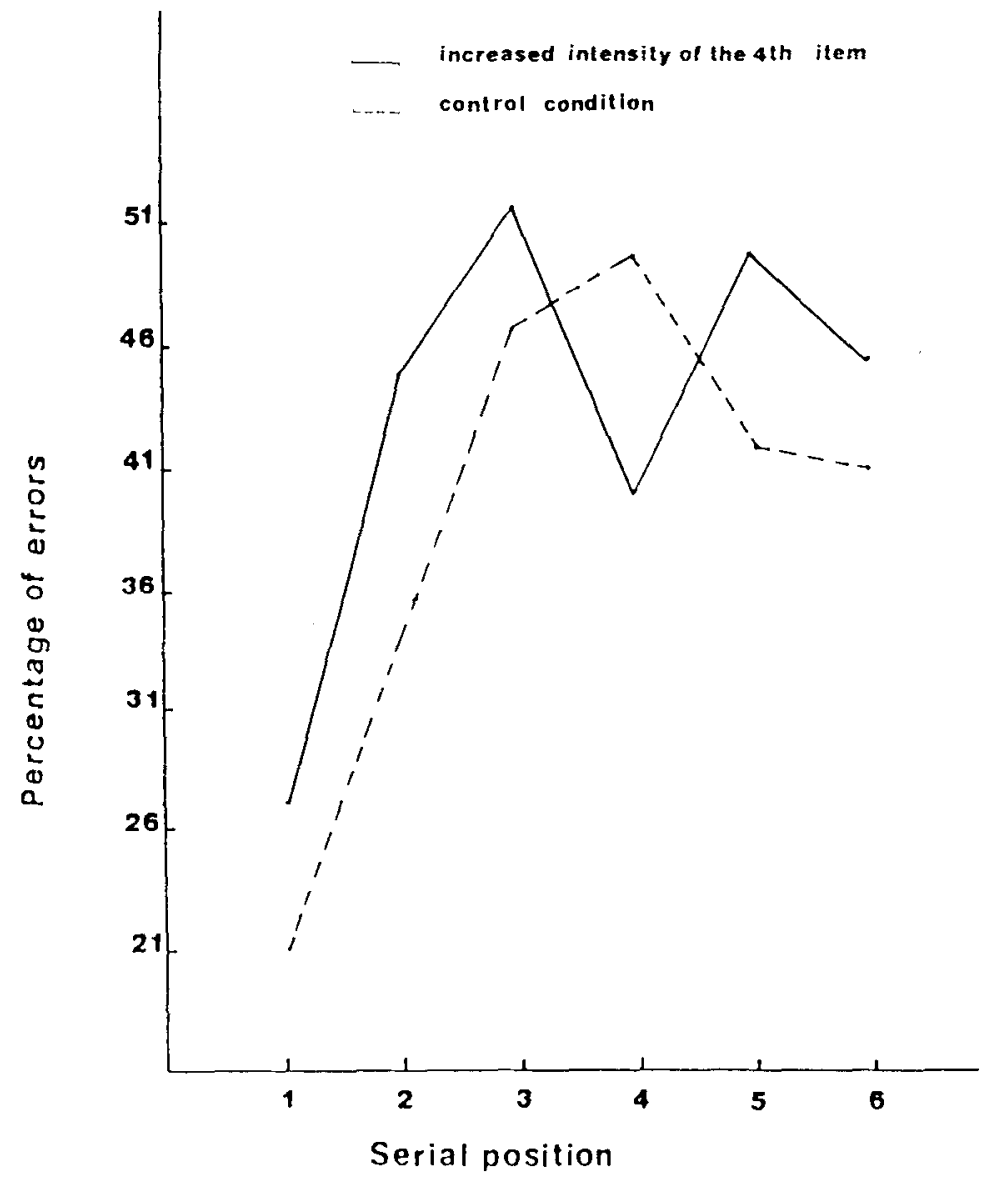

Figure 5. Serial curve for the condition of increased intensity of the fourth item, compared with the control condition (stop syllables). 
list. Thus, it is more parsimonious to consider the recency effect that we obtained as a variety of the von Restorff effect.

\section{GENERAL DISCUSSION}

The alternative theory that our experiments aimed at testing predicts an increase in the final-position recency even with stop-contrasting lists, as a consequence of manipulating (1) certain regular short-term memory mechanisms and (2) item discriminability. Only the latter prediction was supported. These conflicting results can be explained in two ways. First, in Experiment 1, in which short-term memory factors were manipulated, perhaps they were not manipulated effectively enough, or they were not the factors to which the recency effect is sensitive. Second, it is possible that only item discriminability is the critical factor.

Nevertheless, we had some success in supporting a theory that explains the absence of recency effect in stopcontrasting lists without making recourse to echoic memory. In fact, by increasing the discriminability of the last item, a recency effect was obtained for stop lists that makes any explanation in terms of echoic memory difficult or hardly possible.

It must be stressed that our findings do not rule out the contribution of echoic memory, as far as vowel lists are concerned. They simply show that (1) the absence of recency effect for stop lists can be explained in a more parsimonious and consistent way without making any recourse to echoic memory, and (2) mechanisms other than those of echoic memory may contribute to the recency effect (cf. Balota \& Duchek, 1986; Balota \& Engle, 1981; Cowan, 1984; Greenberg \& Engle, 1983).

\section{REFERENCES}

Balota, D. A., \& Duchek, J. M. (1986). Voice specific information and the 20-second delayed-suffix effect. Joumal of Experimental Psychology: Leaming, Memory, \& Cognition, 12, 509-516.

Balota, D. A., \& ENGle, R. W. (1981). Structural and strategic factors in the stimulus suffix effect. Journal of Verbal Learning \& Verbal Behavior, 20, 346-357.

Battacchi, M. W., Pelamatti, G. M., Tessarollo, M., \& Umiltà,
C. (1978). Immediate memory for natural stops and vowels. International Journal of Psycholinguistics, 5, 5-19.

Cowan, N. (1984). On short and long auditory stores. Psychological Bulletin, 96, 341-370.

Crowder, R. G. (1971). The sound of vowels and consonants in immediate memory. Joumal of Verbal Learming \& Verbal Behavior, 10, 587-596.

CROWDER, R. G. (1973). Representation of speech sounds in precategorical acoustic storage. Journal of Experimental Psychology, 98, 14-24.

CRowDER, R. G. (1978). Mechanisms of auditory backward masking in the stimulus suffix effect. Psychological Review, 85, 502-524.

Crowder, R, G. (1981). The role of auditory memory in speech perception and discrimination. In T. Myers, J. Laver, \& J. Anderson (Eds.), The cognitive representation of speech (pp. 167-179). Amsterdam: North-Holland.

Crowder, R. G. (1983). The purity of auditory memory. Philosophical Transactions of the Royal Society of London, B, 382, 251-265.

Crowder, R. G. (1986). Auditory and temporal factors in the modality effect. Journal of Experimental Psychology: Learning. Memory, \& Cognition, 12, 268-278.

Crowder, R. G., \& Morton, J. (1969). Precategorical acoustic storage (PAS). Perception \& Psychophysics, 5, 365-373.

Darwin, C. J., \& Baddeley, A. D. (1974). Acoustic memory and the perception of speech. Cognitive Psychology, 6, 41-60.

Glenberg, A. M., \& SWANSON, N. C. (1986). A temporal distinctiveness theory of recency and modality effects. Journal of Experimental Psychology: Learning, Memory, \& Cognition, 12, 3-15.

GreEnBerg, S. N., \& ENGLE, R. W. (1983). Voice changes in the stimulus suffix effect: Are the effects stnuctural or strategic? Memory \& Cognition, 11, 531-556.

Massaro, D. W. (1972). Perceptual images, processing time, and perceptual units in auditory perception. Psychological Review, 79, 124-145.

Pisoni, D. V. (1973). Auditory and phonetic codes in the discrimination of consonants and vowels. Perception \& Psychophysics, 13, 253-260.

PoSNER, M. I. (1964). Rate of presentation and order of recall in immediate memory. British Journal of Psychology, 55, 303-306.

RYAN, J. (1969a). Grouping and short-term memory: Different means and pattern of grouping. Quarterly Journal of Experimental Psychology, 21, 137-147.

RYAN, J. (1969b). Temporal grouping, rehearsal and short-term memory. Quarterly Journal of Experimental Psychology, 21, 148-155.

voN REsToRFF, H. (1933). Über die Wirkung von Bereichsbildung im Spurenfeld. Psychologische Forschung, 18, 299-342.

(Manuscript received April 6, 1987; revision accepted for publication September 1, 1988.) 